\begin{abstract}
Paco Tovar
Profesor de literatura hispanoamericana en la Universidad de Lleida. Es autor de dos libros fundamentales sobre Augusto Roa Bastos (1987 y 1993), así como de antologías de este autor (1991). Ha publicado numerosos artículos sobre vanguardias latinomericanas, Vicente Huidobro, Juan Carlos Onetti, Mario Monteforte, Alejo Carpentier, etc. Pertenece a varias asociaciones y centros de investigación latinomericanos, siendo miembro fundador 'de la Asociación Española de Estudios Literarios Hispanoamericanos y Secretario General de la misma desde 1992.
\end{abstract}

\section{AL AMOR DE UNA MELODÍA. LA BARCAROLA DE PABLO NERUDA}

PACO TOVAR
1

Las primeras barcarolas son de autor anónimo. No obstante, alguna de esas piezas originales se atribuyen a determinados personajes de los que se guarda memoria. Al ritmo de la barcarola se conservan canciones con letras de Tasso y de Dante. Han incluido la melodía en sus óperas Campra (Les fêtes venettiennes), Harold (Zampa), Rossini (Otello), Weber (Oberon), Auber (La multa di Portici, Fra diavolo y Massinello), o Paisiello (II re Teodoro). De entre las composiciones independientes más conocidas, instrumentales o vocales, se encuentran las barcarolas de Schubert (Auf dem Wasser su singen), Schumann (Myrten, nos. XVII y XVIII), Mendelssohn (Lieder ohne Worte), Chopin (Op. 60), Saint-Säens (La nuit a Lisbonne), Fauré (12 barcarolas para piano) o Bennet (barcarola para piano y orquesta, incluida en su $4^{\circ}$ concierto). Al mismo Chopin armoniza una barcarola muy popular: La biondina in gondoletta.

2

Este volumen de Residencia en la tierra (1931-1935), se publicó junto a la nueva edición de Residencia en la tierra (1925-1931), ambos impresos en Madrid (Cruz y Raya, Ediciones del Árbol, 1935). El poema «Barcarola» se había incluido, meses antes, en El aviso de escarmentados del año que acaba y escarmiento de avisados para el que empieza en 1935, Librocalendarios, Madrid (Cruz y Raya, 1935, pp. 70-72).

El amor de una melodía PACOTOVAR
El término barcarola designaba en su origen un canto de gondoleros venecianos, mimético y frecuentemente improvisado, que llegará a incluirse más tarde en las composiciones de ópera, valorándose como pieza vocal o instrumental independiente durante el romanticismo ${ }^{1}$. En este proceso de configuración, la barcarola conserva sus raíces populares, desplazándolas hacia formas de expresión cultas; evoca situaciones y paisajes amables, adecuando esos referentes a cada circunstancia; mantiene ciertos rasgos líricos, siempre respetando las pautas y el tono de la melodía; y asume su verdadera condición de artificio representativo, rindiendo cuentas de una particular historia común que no extraña momentos de franca intensidad reflexiva. En cualquier caso, la antigua canción veneciana, antes acotada en la realidad de un espacio urbano favorable a las fantasías, pasa a ocupar un lugar significativo en un discurso estético de orden superior y carácter imaginativo, sirviendo de contrapunto independiente a sus secuencias; no deja de acumular motivos y escenas, proyectando sus visiones más allá de los límites que se les reservaba en un principio; y adquiere dimensiones simbólicas, ajustándose a las leyes del propio sistema expresivo. Todos esos antecedentes tendrán su correlato en la literatura, sin confundir nunca las reglas que deben observarse para efectuar el consecuente ejercicio de adaptación.

\section{SI SOLAMENTE ME TOCARAS EL CORAZÓN}

Uno de los poemas que Pablo Neruda integra en su segunda Residencia en la tierra ya se titula "Barcarola" 2 . La identidad de la pieza no es arbitraria; tampoco su localización dentro del libro. Avalada por una tradición, responde a los propósitos del autor: se articula en el momento oportuno, comprendiendo en unos pocos versos la preocupación del hombre corriente y la aventura de quien trata de contarlas. Estos resgistros se inician imponiendo sus condiciones, permiten llevar a cabo ejercicios comparativos, exigen delimitar espacios concretos, reclaman la atmósfera adecuada, se expanden por un tiempo diluido en la conciencia y proclaman, desde su reclusión, un canto de sirenas o una antigua balada de prisionero.

Para realizar la tarea cordial de su escritura, tomándole el pulso a la composición, Neruda plantea la necesidad de recibir sensaciones que estimulen la piel y remuevan las entrañas del poeta, siendo éste el responsable de acordar esa dinámica a la de una naturaleza que también entiende de progreso. La canción que resulta, con su timbre sensual, elige el amor y la soledad como temas dominantes; decide el carácter de sus armónicos, señalando fugas y recurrencias; y marca el ritmo de un decir que, entre su realidad y la sombra de sus deseos, sabe de estancias en la tierra:

Así es, y los relámpagos cubrirían tus trenzas y la lluvia entraría por tus ojos abiertos a preparar el llanto que sordamente encierras, y las alas negras del mar girarían en torno de tí con grandes garras, y graznidos, y vuelos.

Quieres ser el fantasma que sople, solitario, cerca del mar su estéril, triste instrumento? 
Si solamente llamaras,

su prolongado son, su maléfico pito,

su orden de olas heridas,

alguien vendría acaso,

alguien vendría,

desde las cimas de las islas, desde el fondo rojo del mar,

alguien vendría, alguien vendría.

Alguien vendría, sopla con furia,

que suene como sirena de barco roto,

como lamento,

como un relincho en medio de la espuma y la sangre,

como un agua feroz mordiéndose y sonando.

\section{En la estación marina}

su caracol de sombra circula como un grito, los pájaros del mar lo desestiman y huyen, sus listas de sonido, sus lúgubres barrotes se levantan a orillas del océano solo. ${ }^{3}$

\section{ES LA HORA, AMOR MÍO, DE APAR- TAR ESTA ROSA SOMBRÍA}

Al concluir su Memorial de Isla Negra, Pablo Neruda incluye en primera instancia los veintiún fragmentos que integraban la serie «Amores: Matilde», más tarde suprimidos de ese corpus general para iniciar La Barcarola ${ }^{4}$, siendo éste ya un libro de poemas independiente que se articula dentro de la obra completa del escritor. El cambio de orden, y la supresión del título que antes daba pie al resto del discurso, tampoco son un capricho de Neruda: vienen a confirmar la coherencia de una tarea literaria que tiende a localizar sus elementos en el espacio más conveniente, sin perder en ningún momento el tono de la historia. El resultado de estas variaciones acuerda con las antiguas canciones venecianas, prestando atención a sus voces anónimas y a sus registros cultos; guarda memoria de ellas cuando se utilizan como parte de un complejo musical escenificado; atiende a su consideración lírica, con perfiles épicos, todos asumidos durante el romanticismo; y alcanza a superar esas fases, rindiendo oportuno testimonio de la propia naturaleza simbólica.

De nuevo es el amor, entendido como relación principal y como tema poético dominante, el que alimenta la melodía en sus diferentes planos expresivos: uno, reservado para discurrir por un paisaje íntimo, revelando en ese sitio la secreta aventura de un suje-

to cargado de experiencia; el otro, dedicado a las impresiones, da noticias de una conciencia ensimismada que se descubre en cualquier lado y en sucesivas etapas; los dos, reunidos a solas, para contemplar de frente las visiones que surgen al tiempo de un espacio concreto; todos, personifican desde el principio en un cuerpo que sabe de causas, conoce efectos y sigue interrogando a la esfinge:

Amante, te amo y me amas y te amo:

son cortos los días, los meses, la lluvia, los trenes: son altas las casas, los árboles, y somos más altos: se acerca en la arena la espuma que quiere besarte: transmigran las aves de los archipiélagos y crecen en mi corazón las raíces del trigo.

No hay duda, amor mío, que la tempestad de cayó con su hierro oxidado sobre tu cabeza y cuando, entre rachas de espinos te vi caminando [indefensa, tomé tu guitarra de ámbar, me puse a tu lado, sintiendo que yo no podía cantar sin tu boca, que yo me moría si no me mirabas llorando en la lluvia.

Porque los quebrantos de amor a orillas del río, porque la cantata que en pleno crepúsculo ardía en [mi sombra, por qué se encerraron en ti, chillaneja fragante,

3

Pablo Neruda, "Barcarola", Residencia en la tierra. 2, en Obras completas de Pablo Neruda, Buenos Aires, Editorial Losada, 1973 4, vol. I, pp. 212-213.

A propósito de esta misma "Barcarola", Amado Alonso expone ciertos citerios analíticos, seleccionando previamente los fragmentos a los que hace referencia (Poesía y estilo de Pablo Neruda, Barcelona, Pocket Edhasa, 1979). Opina el crítico que, en ciertos momentos de la pieza, no domina el designio de embellecer los símbolos, proporcionando así sensaciones agradables, sino que se prefiere utilizar el feísmo como caregoría estética. También se apuesta por la nostalgia y la melancolía, anclando con una los propios recuerdos y dando paso con la otra a la tristeza poco se reprime en sus aprecios: destaca la madurez de unos versos que alcanzan cotas de verdadero delirio lírico. Porque es «el sentimiento -lo más específico y lo más irracional de la poesía-, lo que constituye aquí para el poeta el centro de atención y el germen estructurador, $y$, a la vez, el hilo de Ariadna para el lector» (Amado Alonso, op., cit. p. 190).

4

Memorial de Isla Negra se publica en varias entregas. La primera, acompañada de un prólogo del autor, se tituló en su momento Sumario. Libro donde nace la Iluvia (Alpignano, Italia, Alberto Tallone impresor, 1963), modificando en parte esa identidad al imprimirse de nuevo, sin prólogo, como Memorial de la Isla Negra: I. Donde nace la lluvia (Buenos Aires, Losada, 1964). Le siguen Memorial de la Isla Negra: II. La luna en el laberinto (Buenos Aires, Losada, 1964); Memorial de la Isla Negra: III. El fuego cruel (Buenos Aires, Losada, 1964); Memorial de la Isla Negra: IV. El cazador de raices (Buenos Aires, Losada, 1964); y Memorial de la Isla Negra: V. Sonata crítica (Buenos Aires, Losada, 1964). La serie íntegra, ya comprendida con el título genérico común, se da a conocer entre el 2 de junio y el 12 de julio del mismo año, concluyendo el último libro con el fragmento "Amores: Matilde», siguiendo éste las pautas fijadas en anteriores poemas, todos en el conjunto de La Isla Negra, de similar intención: «Amores: Teresa» (dos piezas); "Amores: Rosaura» (dos piezas); «Amores: Rangoon 1927»; "Amores: Josie Bliss» (dos piezas), y «Amores: Delia» (dos piezas).

La Barcarola se publica en diciembre de 1967 (Buenos Aires, Losada, edición al cuidado de Margarita Aguirre $y$ Andrés Ramón Vázquez), iniciándose el volumen con gran parte de los versos de "Amores: Matilde», suprimidos de su anterior localización.

Todas estas referencias pueden servir para confirmar la recurrencia temática nerudiana; también para seguir las huellas de ciertas variantes en su obra que acuerdan con los ajustes oportunos de sus diferentes piezas.

El amor de una melodía PACO TOVAR 
5

"Te amo", La Barcarola, en O.C. op. cit. vol III. p. 89. En adelante, si no se advierte lo contrario, todas las citas remiten a poemas de este libro de Neruda, en su edición dentro de las Obras completas de autor.

El amor es una de las notas dominantes en la poesía de Neruda. Su registro no tiende hacia la abstracción del sentimiento sino que responde a estímulos concretos, localizando en cada momento quién es el sujeto femenino que sirve de referente al escritor, estimulado éste por la relación. En ocasiones, ella se presenta con su nombre; otras se esconde tras una situación o una anécdota determinadas; $y$, con frecuencia, es la piedra de toque en una historia representada capaz de comprender a la mujer en una realidad de amplio espectro.

En La Barcarola se encuentra Matilde Urrutia, la misma mujer a la que Neruda dedica, cuando menos, sus Cien sonetos de amor (Santiago, Prensas de la editorial Universitaria, 1959).

6

"En las calles de Praga", p. 90.

7

"El amor", p. 94. y restituyeron el don y el aroma que necesitaba mi traje gastado por tantas batallas de invierno? ${ }^{5}$

Tan pocos versos bastan para desvelar algunas incógnitas, sin exhibir otros secretos que no sean imprescindibles. Ella está ahí, otra vez callada y ausente, sirviendo de estímulo a quien canta con nostalgia la angustia obsesiva de un presente lleno de recuerdos; ayudando a generar un diálogo que se mueve al son de ciertas palabras; cuestionando la influencia que ejerce sobre un espíritu posesivo; y devolviéndole a este fantasma la gracia perdida con el paso de las estaciones repletas de frío.

De inmediato, se organiza una memoria selectiva, meciéndose ésta a tenor del balanceo apropiado a los registros de La Barcarola. Se evocan así las calles de Praga, unidas a la imagen de la amada, que se contempla como un fruto exótico sobre el puente de Carlos; se utiliza este paso para llegar a Budapest, una vez superada la nieve de siete fronteras; y se cita donde

...los amantes, tú y yo, perseguidos, sedientos y [hambrientos

nos reconocimos hiriéndonos con dientes y brazos y [espadas.

Oh días cortados por las cimitarras del fuego y la furia sufriendo el amante y la amante sin tregua y sin llanto como si el sentimiento se hubiera enterrado en un [páramo entre ortigas y cada expresión se turbara quemándose y

[volviéndose lava. ${ }^{6}$

La unión entre los dos-uno-solo revela ese gran territorio nerudiano, dominado por la relación amorosa, convirtiendo lo abstracto en concreto sin negar su contrario. Dolor y gozo, fuego y piedra, componen un acto poético, que también se cumple luchando con las palabras, modulando la voz y contando historia. Todo remite al fondo del tú y al fondo del yo, descubriendo ahí la ceguera de quienes viven adentro de un pozo que ardía con nuestras tinieblas.

El vaivén inclina la barca hacia otros paisajes: atrás queda una geografía triste; de frente se contempla otra con perfiles de Italia y puerta romana. El mutuo abrazo, que se perfuma con aromas de jazmín crecido en gritos de roca, marca ahora con gozo el rum- bo de aquellos que anclaron en Capri, miran su aislado horizonte marino, se arropan entre los que parecian extraños y valoran los sueños. Ellos mismos, a veces, se hunden en la nostalgia o se amparan en las penas del destierro, pero siempre mantienen en secreto público la realidad del propio misterio genésico:

Te amé sin por qué, sin de dónde, te amé sin mirar, [sin medida y yo no sabía que oía la voz de la férrea distancia, el eco llamando a la greda que canta por las cordilleras, yo no suponía, chilena, que tú eras mis propias raíces, yo sin saber cómo entre idiomas ajenos lé el alfabeto que tus pies menudos dejaban andando en la arena y tú sin tocarme acudías al centro del bosque invisible a marcar el árbol de cuya corteza volaba el aroma [perdido?

Es la amiga quien se presenta como un rito que saca las cosas de su letargo, remueve la tierra, amasa los signos, dispone de colores y traza, desde el abismo, la calzada que une cualquier suelo con su particular bóveda celeste.

Esa mujer también se amolda a las cadencias de una melodía que llega a tomar el pulso del que continúa picando las piedras, la sombra, el vacio; a restituir el cristal quebrantado en el fondo del ser; a sostener el minimo reino recién descubierto; a viajar por mares de vuelta a la raza, a la berencia, al recinto; a despertar el idioma perdido que fluye por las cabelleras en tierras ajenas; a sufrir la experiencia de Jonás en bodegas de barcos; a estar en casas o construir hogares con nombres propios; y a despertar en la noche con ella, ambos perdidos en cualquier parte.

Una y otro, unidos, dominan sus territorios, fijando juntos su mayor nota dominante, cantada desde el origen y sentida hasta ese mismo destino. Ya en el inicio de La Barcarola, impera el mapa chileno sobre otros lugares de inevitable tránsito, siendo estos últimos los puentes de unión entre el fuego y el frío entrañables. Universo tan amplio, se reduce completo en los límites de La Chascona y La Sebastiana, por entonces sendas radas de amarre nerudiano. Más aún, todo ese mundo cabe, con faros y muelles, en reflejos de una mirada que se entrega proclamando estar repleta de verdaderas aventuras imaginarias:
El amor de una melodía PACO TOVAR 
he aquí, sosteniéndose en hilos, en uñas, en enredaderas, he aquí, victorioso, harapiento, color de campana y de miel, he aquí, bermellón y amarillo, purpúreo, plateado, violeta, sombrío y alegre, secreto y abierto como una sandía el puerto y la puerta de Chile, el manto radiante de

[Valparaíso,

el sonoro estupor de la lluvia en los cerros cargados de [ padecimientos,

el sol resbalando en la oscura mirada, en los ojos más

[ bellos del mundo. ${ }^{8}$

El sonido de los amantes continúa vigente al ocupar sus plazas siguiendo el ritmo de La Barcarola, que tampoco niegan su condición eterna:

Es ahora la hora y ayer la hora y mañana es la hora: mostramos saliendo al mundo la dicha impecable y déjame oír que tus pasos que traen la cesta del pan [y perdices

suenan entreabriendo el espejo del tiempo distante y [presente

como si llevaras en vez de canasto selvático mi vida, tu vida: el laurel con sus hojas agudas y la

[ miel de los invulnerables. ${ }^{9}$

Sigue así la canción, anunciando otra vez regresos, marcando de nuevo distancias, incluyendo momentos oportunos y determinando rasgos de identidad literaria que, en última instancia, late en el pecho de comunes agonizantes:

Yo cambié tantas veces de sol y de arte poética que aún estaba sirviendo de ejemplo en cuadernos de [melancolía

cuando ya me inscribieron en los nuevos catálogos [de los optimistas,

y apenas me habían declarado oscuro como boca de [lobo o perro

denunciaron a la policía la simplicidad de mi canto y más de uno encontró profesión y salió a combatir [mi destino

en chileno, en francés, en inglés, en veneno, en [ladrido, en susurro.

Aquí llevo la luz y la extiendo hacia el mal compañero La luz brusca del sol en el agua multiplica palomas, y [ canto.

Será tarde, el navío entrará en las tinieblas, y canto. Abrirá su bodega la noche y yo duermo cubierto de [estrellas. Y canto.
Llegará la mañana con su rosa redonda en la boca. Y [yo canto.

Yo canto. Yo canto. Yo canto. Yo canto. ${ }^{10}$

Blandiendo esa bandera, continúa $L a$ Barcarola superando las etapas que restan al compás del tiempo. Sobre ese mapa cronológico, sencillo y complicado a la vez, se ordena la danza de unas imágenes que arrastran sensaciones, recuerdos, ilusiones, noticias, itinerarios y pistas de una conciencia que se va meciendo con quiebros de navegante o se ajusta a las presiones de una mano firme que sabe dirigir el cuerpo de su pareja a tono con la música del baile. Ahí están los años, un día, muchas jornadas; también un milagro de resurrección, las campanas que tocan el rocío en el bronce de los campanarios, los impulsos acordados con la amante y la sonata guardada en el arca de los cuerpos vivos. Se añade el bullicio de una calle emblemática, la sorpresa de estar amaneciendo, la noche que cambia los cuerpos hasta la llegada del alba, el país divisado al pie de unos ángeles con zapatos nuevos, la primavera de Chile y el breve anuncio de un cuento que ilustrará, con sangre y oro, su misma otra muerte lejana.

Hasta se incluye, después de un paisaje diurno, ante el mar, a tiempo, con sitios, en tránsito y tras un claro de sol, una barcarola dentro de La Barcarola. Dejando nueva constancia de un diálogo entre pares alternos, por un lado, llegan de dentro las voces de afuera, descubriéndose ese rasgo en el libreto con oportuna cursiva parentética; por otra parte, se sitian fuera las palabras que están adentro, dichas en perfiles de letra corriente. Las dos fuerzas plantean la naturaleza del hombre que cuenta sobre la tierra a favor del viento.

Y todavía sigue la composición, exponiendo en ella soledades, bosques, pájaros, pueblos y aguas; claves de sol, idas y vueltas, explicaciones y ofrecimientos. Concluye al fin la melodía con versos en clave de sal. El poema se suspende al caer por los labios las escenas adecuadas de su representación:

(De pronto el día rápido se transformó en tristeza y asi la barcarola que crecía cantando se calla y permanece la voz sin movimiento).

Así cuando tantos presagios llevaban al fin de mi vida,
"La Chascona", p. 99.

En cualquiier caso, la mujer es el lugar constante donde se sostienen los recuerdos del viajero, todos desprendidos como fina ceniza celeste de los ojos de ella; todos depositados sobre sus vestidos teñidos del mismo color celestial. El poeta rinde así perdido homenaje a mil años de ausencia, dando cuenta de que todo parece en el sueño más vivo como si la tierra sedienta, violada [y nutricia,

quisiera extender el mandato y el [puño vacio de cúpulas, tumbas, mezquitas, y [de su esplendor equilibrado. ("Viajeros", op. cit. p. 102).

9

"Los invulnerables", pp. 106-107. No es difícil rastrear en la obra de Neruda gran parte de los materiales poéticos comprendidos en La Barcarola. Junto a la nota dominante que representa a la mujer, descubriendo la amplitud de la relación amorosa, se descubren otros motivos de importancia, extrayéndolos de la memoria: sucesos, escenas cotidianas, anécdotas personales, figuras entrañables y hasta marcas ideológicas o políticas, todos comprendidos en el universo poético del viajero, rindiendo así cuenta de su aventura principal y de sus armónicos.

10

"Estoy lejos", p. 113.

Pablo Neruda no se traiciona a sí mismo cuando se identifica en La Barcarola, añadiendo en esta pieza un trazo más a su perfil literario. Sus rasgos se distribuyen en "Arte poética" $17^{9}$ Residencia en la tierra, 1933); "El poeta" (Canto general, 1950); "Yo canto y cuento" y "Te construí cantando" (Las uvas del viento, 1954); "Termina su libro el poeta hablando de sus variadas transformaciones y confirmando su fe en la poesía" (Extravagario, 1958); "Deber del poeta" (Plenos poderes, 1962); "Arte magnética" (Memorial de la Isla Negra, 1963); "El canto" (Las manos del dia, 1968); y "Artes poéticas I", "Artes poéticas II" (Fin de mundo, 1969). Reuniendo la totalidad de esos registros se completa la imagen poética nerudiana.

El amor de una melodía PACO TOVAR 
12

“Primer episodio: Terremoto en Chile", p. 102.

13

"Tercer episodio: Crónica del archipiélago para Rubén Azócar", pp. 117-118.

También dedica Neruda un poema a su amigo Rubén Azócar en Canto general. los altos tambores, las trenzas floridas, los centelleantes [tobillos

-danzaban sonriendo y cantando para un extranjero.

Te canto este cuento, amor mío, porque la enseñanza del hombre se cumple a pesar del extraño atavío y allí se fundaron en mí los principios del alba, allí despertó mi razón a la fraternidad de los hombres.

Amor mío, canté para ti los transcursos de mar y de día, y fue soñolienta la luna de mi barcarola en el agua porque lo dispuso el sistema de mi simetría y el beso incitante de la primavera marina.

Te dije: a llevar por el mundo del viaje tus ojos amados! La rosa que en mi corazón establece su pueblo fragante! Y, dije, te doy además el recuerdo de pícaros héroes, el trueno del mundo acompaña con su poderío mis besos, y así fue la barca barquera deslizándose en mi barcarola.

Es la hora, amor mío, de apartar esta rosa sombría, cerrar las estrellas, enterrar la ceniza en la tierra:

y en la insurrección de la luz, despertar con los que [despertaron

o seguir en el sueño alcanzando la otra orilla del mar [que no tiene otra orilla. ${ }^{11}$

\section{LOS EPISODIOS}

Los sucesivos movimientos de La Barcarola, excepto el último, se acompañan de unas historias que no sólo ilustran con sus armónicos el sentido de la serie anterior, sino que descubren pedazos de una memoria que se va decantando desde el suceso natural hasta la propia conciencia del hombre, pasando por fases de oportuna revelación. El terremoto que asoló Chile, afectando en mayor grado a la ciudad de Valparaíso y, en consecuencia, a las posesiones que en ese lugar tenía Neruda, deja de ser un desastre público o un despojo personal para convertirse no tanto en simple motivo literario como en símbolo material de una tragedia. El hecho se descubre desde la ausencia, sume en la impotencia a quien sabe entender el fenómeno como el gesto arbitrario de un dios soberbio y hasta lo acusa, sin creer en él, por elegir de nuevo sus víctimas en cotos que soportan castigos antiguos:

Dios mío, tocó la campana la lengua del antepasado en [mi boca

otra vez, otra vez el caballo iracundo patea el planeta y escoge la patria delgada, la orilla del páramo andino, la tierra que dio en su angostura la uva celeste y el cobre [absoluto, otra vez, otra vez la herradura en el rostro de la pobre familia que nace y padece otra vez el espanto [y la grieta,

el suelo que aparta los pies y divide el volumen del alma hasta hacerla un pañuelo, un puñado de polvo, un gemido. ${ }^{12}$

Con rostro de penitencia bíblica y al hilo de crónicas periodísticas, se levanta la imagen lírica de un espectáculo dramático que adquiere dimensiones épicas. No es el testigo quien habla; es el hombre que siente entero la magnitud devastadora, ignorando si la tierra muere porque él se ha muerto y pensando si no es al revés. En cualquier caso, las ruinas alimentan el canto.

La segunda viñeta se resuelve en París, también en 1965. La ciudad es la que tiene hermosas calles, la que goza de un pobre esplendor opulento en sus escaparates, la que recoge beatnicks barbudos y acoge un tú y un yo transmigrados en estrellas, ambos felices $y$ sordos cuando lejos tiembla la lluvia de la patria.

Junto a la escena precedente, la que muestra esa capital francesa no deja de ser refugio de soledades, sepulcro de un Vallejo que allí se entierra, recuerdo de Crevel a partir de una esquela leída en cualquier diario comprado de paso en la estación de Burdeos, Isla de Saint Louis que arropa a los amantes, luciendo una sus galas y el otro pensando en la carne que se esconde bajo el vestido que la adorna.

Procedente de Chile, llega la sombra de un cadáver amigo, instalándose en el tercer episodio. Es la presencia de Rubén Azócar, el que

...paseaba en Boroa, en Temuco con un charlatán sinalefo, con un pobre ladrón de gallinas vestido de negro que estafaba, servil y silvestre, a los dueños del fundo, era un perro averiado y roído por la enfermedad literaria que a cuento de Nietzsche y de Whitman, se disimulaba [ladrando

y mi pobre Rubén antagónico soportaba al pedante [inclemente

hasta que el charlatán lo dejó de rehén en el pobre [hotelucho sin plata y sin ropa, en honor de la literatura. ${ }^{13}$

Dentro del mazo de cartas, jugadas aquella tarde, ya falta el rey que se fue para siempre con la risa y la rosa en la mano.

Se añade la imagen poética de Joaquín Murrieta en el cuarto episodio, dando noti- 
cias de un difunto emblemático en la obra de Neruda. A veces, la figura permite rastrear sus pasos; en ocasiones, se enseña la representación de los diálogos que mantiene con su Teresa; también es parte de un cuento histórico en verso o no elude componerse en estrofas casi canónicas de diversa índole y distinto tono. Siempre encarna al Pueblo que con él repite el sonido permanente de una campana más tarde tañida en larga cantata de luto ${ }^{14}$.

Se escuchan repiques de bronce en el quinto episodio. En Rusia tocan a paz y llaman a gloria de amores eternos, todos en la órbita de muchos hombres recientes. No falta después la cita obligada con Darío. Éste, en el sexto episodio, se encuentra

...en las calles de Valparaíso, esmirriado aduanero, singular ruiseñor que nacía: era él una sombra en las grietas del puerto, en el

[humo marino,

un delgado estudiante de invierno desprendido del [fuego de su natalicio.

Bajo el largo gabán tiritaba su largo esqueleto y llevaba bolsillos repletos de espejos y cisnes: había llegado a jugar con el hambre en las aguas de [Chile,

y en abandonadas bodegas o invencibles depósitos de [mercaderías,

a través de almacenes inmensos que sólo custodian [el frío,

el pobre poeta paseaba con su Nicaragua fragante, [como si llevara en el pecho un limón de pezones azules o el recuerdo en redoma [amarilla. ${ }^{15}$

El diálogo con ese fantasma lo plantea Neruda en el presente de un pasado magisterio. Así da fe de sus sueños en las calles de Valparaíso, invoca las glorias y aciertos de un personaje que aprecia y discute, propone hablar con su otro, proclamando honores a su citara eterna, a su torre indeleble.

$\mathrm{Y}$ viene el séptimo episodio con Lord Thomas Cochrane, recompuestos con cuidado los trozos que el escocés ha dejado en Chile. Al transcribir parte de uno de sus discursos, pretende Neruda conservar el talante de un comerciante político que fue amenazado por los enemigos del progreso que el militar navegante dictaba en la Cámara a contrapelo de mentes rancias. No caben ideales de cuño moderno en cerebros casti- zos, y eso pierde al marino que sigue con sus aventuras a cuestas, logra triunfos y se despide anclando definitivamente en la historia de su tierra adoptiva.

No falta puesto a una cita brasileña, situada en el noveno episodio. El lugar se llama Santos, acoge al visitante con la bandera de un Pelé mítico recogido en la voz viva de alguien que conoce al atleta porque la televisión le gusta. Pero no es eso lo que cuenta, sino lo primitivo del muelle, el calor del país o la identidad de un barco o la visión de otros sin nombre leído. En semejante medida, se aprecia la escenografía religiosa de un paisaje industrial, los juegos de azar, el café y otra vez el calor húmedo. Así se describe Santos, que en el otro bemisferio respeta el cemento creciente.

Interviene en su momento un sujeto en pedazos de América llamado Chivilcoy. Contrasunto nerudiano, reconoce un yo que cambia

...de rumbo, de empleo, de bar y de barco, de pelo de tienda y mujer, lancinante, exprofeso no existo, tal vez soy mexibiano,argentuayo, bolivio, caribián, panamante, colombovenechilenomalteco. ${ }^{16}$

Vende pronto en los mercados, compra caminando y se inscribe en partidos dispares, según las necesidades rituales que echan a la mierda el crepúsculo. Igual confiesa sáber más que todos sin haber aprendido, y admite que aquello que ignora no vale la pena, no se paga en la plaza, señores.

Chivilcoy se mezcla con el escritor, aunque no se confunden. Mal vestido y peor calzado, el reflejo lleva un gran anillo y se le cuida como un animal exótico. Se casó con hembras, no sabe dónde, siguiendo ritos de orden extraña. Cambió de residencia sin demasiados problemas y aún valora a la mujer que supo darle placer en la cama. Ejerció de mercachifle en sitios que van de Perú hasta la Patagonia. Duerme, con su orgullo, en pensiones baratas, tomándose por pobre entre ricos, sin haber perdido nada en el disimulo.

Asomado a la ventana que le corresponde en la vida, mira el paisaje urbano que le toca en suerte, espía ahí los mismos bichos cuando orinan y cuando buscan felicidad o mierda. Y, para terminar su dibujo, dice no haber perdido todavía el erotismo que tiene el gato, copiando el desinterés del animal por las biografías ajenas. Está claro que no es nadie y es
14

La cita de Neruda refiere a su pieza teatral Fulgor y muerte de Joaquín Murrieta (Santiago, ZigZag, 1967).

15

"Sexto episodio: R.D. I. Conversación marítima", p. 152.

16

"Décimo episodio: Habla un transeúnte de las Américas Ilamado Chivilcoy. 1", p. 172.
El amor de una melodía PACO TOVAR 
17

Ibid., p. 193.

18

"Doceno episodio: La máscara marina". pp. 179-180.

19

"Solo de sal", op. cit. p. 182. todo, conformándose con lo poco que tiene que dejar en herencia: un trozo de músculo que salta de entre sus piernas.

Si desaparezco aparezco con otra mirada: es lo mismo. Soy un héroe imperecedero; no tengo comienzo ni fin y mi moraleja consiste en un plato de pescado frito. ${ }^{17}$

El décimo episodio, penúltimo de la serie, disfraza al hombre de astronauta, montando por elementos su farsa. Un día se encontró plantado el humanoide, por equivocaciones de padre y madre, en un baldío. Nota desde entonces que se aburre, que deja de fumar puros, que desencadena ramalazos de locura y que practica la hipocresía. Aquí llegó porque lo invitaron a una trampa; porque no necesitaba más ropa que su lengua; porque desconocía el daño que causa el tiempo, la envidia y el cinismo; porque menos sabía de una sociedad frívola, dicharachista y restaurada con productos cosméticos. Y aquí se pierde bajo el caudal de un gran río de esmeraldas que no sabian contar.

Por fin se cierra el círculo de referencias, mirando el escritor su propia máscara marina. Suave, pasa materializando abstracciones comunes o sacando de sus cajas íntimas sólidos regalos vitalistas. Convertido en estatua de sal transparente en la lluvia, y dentro de morada señora, ofrece crepuscularios al viento y a la noche; permanece sólo con su alma, amándose los dos al tiempo que circulan por la historia dibujando planos con centros en los cuatro puntos cardinales y capital chilena:

...yo sigo yo sumo

no muevo los ojos no canto no tengo palabras no sueño me mueven me cantan me sueñan me sume la ola salpica levanta mi desventurada cabeza en la eterna [intemperie yo vivo en el gran movimiento del orbe en la nave soy parte incesante de la dirección de la esencia no tengo contrato firmado con gotas de sangre ni reina

[ni esclava

y sólo obedezco al latido del agua en la proa como una [manzana obedece a la savia que sube y navega en el árbol de la [primavera y yo me incorporo al camino mis ojos no saben llorar soy solo una forma en la luz una vértebra de la alegoría. ${ }^{18}$

\section{...SALTANDO DE AQUÍ PARA ALLÁ...}

No hacen falta demasiadas luces para reconocer que Neruda, al componer La Barcarola, no sólo tiene en cuenta el origen musical de la pieza, siguiéndole el rastro a su posterior evolución melódica; también plantea la naturaleza particular de un universo literario que se mueve al ritmo del corazón, sigue el compás de la historia y adquiere verdadera categoría simbólica. El escritor, seducido por el canto, no persigue a las sirenas; se apropia de sus ecos sin caer en la trampa de invadir el territorio reservado a otros oficiantes ni ocupar plaza de melómano impenitente. Sabe que su tarea debe resolverse en versos, ofreciendo en ellos la última clave de un proceso que se mantiene en vilo gracias a ciertas notas dominantes, acompañados de sus armónicos; a la fuerza de oportunos rasgos líricos, con sus adecuados tonos épicos; a firmes ejercicios de conciencia, repletos de fugas; y a un decir que, en última instancia, llega a identificarse con la humanidad del propio discurso, recogiendo en él los restos de una canción íntima que se mece desde antiguo y aún continúa sintiéndose en el aire, saltando de aquípara allá:

Si nunca la nave en su imperio regresa con dedos intactos si la barcarola seguía su rumbo en trueno marino y si tu cintura dorada vertió su belleza en mis manos aquí sometemos en este regreso del mar, el destino, y sin más examen cumplimos con la llamarada.

Quién oye la esencia secreta de la sucesión, de la sucesiva estación que nos llena de sol o de llanto? Escoge la tierra callada una hoja, la ramificada postrera y cae en la altura amarilla como el testimonio de un [advenimiento. ${ }^{19}$ 